\title{
AQUISIÇÃO DAS CATEGORIAS LEXICAIS E GRAMATICAIS DO ASPECTO DA LÍNGUA BRASILEIRA DE SINAIS: CRIANÇA SURDA COM E SEM IMPLANTE COCLEAR
}

\author{
ACQUISITION OF LEXICAL AND GRAMMATICAL CATEGORIES OF THE \\ ASPECT OF BRAZILIAN SIGN LANGUAGE: \\ DEAF CHILDREN WITH AND WITHOUT COCHLEAR IMPLANT
}

Lídia da Silva*

\begin{abstract}
Resumo: 0 objeto de estudo desta pesquisa é aquisição da categoria aspectual por duas crianças surdas, sendo que uma delas passou pelo procedimento cirúrgico de implante coclear (IC). Nossa pergunta norteadora é se as hipóteses que se ocupam em explicar o processo de aquisição da categoria aspectual por uma criança surda apontadas em Silva (2010) se aplicam também à criança surda que tem IC. Para refletir sobre isso, tomamos Comrie (1976) e Finau (2004) e, em ambos, as considerações linguísticas recaíram sobre o enfoque lexical e gramatical do aspecto e sobre a oposição entre perfectivo e imperfectivo. Nossa pesquisa é de natureza espontânea e os sujeitos investigados são crianças com pseudônimos de ANA e BRUNO. Ambos são surdos, filhos de pais surdos e estavam adquirindo a Libras como sua primeira língua. ANA e BRUNO foram filmados por mais de três anos e todos estes dados são do corpus do grupo de pesquisa sobre aquisição de língua brasileira de sinais da UFSC, dirigido por Ronice Muller de Quadros. Para transcrição, adotamos Sistema de Notação por Palavras (FELIPE, 1998). Em análise, percebemos que tanto ANA quanto BRUNO produzem predominantemente aspecto lexical perfectivo e que as produções de aspecto gramatical ocorrem via flexão. Essas flexões ocorrem por meio de alteração morfológica (movimento), e são de ordem perfectiva, majoritariamente. Com isso, identificamos que uma criança surda que tem estimulação da língua oral, por meio da presença do IC e, por consequência, uma orientação bilíngue/bimodal, apresenta as mesmas produções linguísticas da categoria aspectual em Libras de um usuário monolíngue desta língua. Ou seja, identificamos que as mesmas hipóteses que explicam o processo aquisicional da categoria aspecto por uma criança surda apontadas em Silva (2010) se aplicam também à criança surda que tem pais surdos e que tem IC.
\end{abstract}

Palavras-chave: Aspecto; Aquisição da linguagem; Libras; Implante coclear;

\begin{abstract}
The present study investigates the acquisition of the aspectual category of two deaf children, one of whom underwent cochlear implant (CI) surgery. Our question is whether the hypotheses raised by Silva (2010) to explain the process of acquisition of aspectual category of a deaf children also apply to the deaf child who has a CI. The present study is based on both Comrie (1976) and Finau (2004), who focused on lexical and grammatical aspects and the opposition between perfective and imperfective. Our research is spontaneous in nature; we investigated children whose pseudonyms were ANA and BRUNO. Both are deaf children of deaf parents and were acquired Libras (Brazilian Sign Language) as their first language. ANA and BRUNO were filmed over three years; the data are part of the corpus of the research group on the acquisition of Brazilian Sign Language at UFSC, which is coordinated by Ronice Muller de Quadros. The transcription of data was
\end{abstract}

\footnotetext{
* Doutoranda do Programa de Pós-Graduação em Linguística da Universidade Federal de Santa Catarina.
} 
carried out using the notation Sistema de Notação por Palavras (FELIPE, 1998). In the analysis, we observed that ANA as well as BRUNO produced, predominantly, the perfective lexical aspect; we also observed that the grammatical aspect of the productions occur via bending. These inflections occur through morphological change (movement); and they are mostly perfective. Our results show that a deaf child who has spoken language stimulation, through the presence of $\mathrm{CI}$, and therefore, a bilingual/bimodal orientation, has the same linguistic category aspectual production in Libras as a Libras monolingual user. The hypotheses that explain the process of acquisition of aspectual category of a deaf child presented in Silva (2010) also apply to a deaf child with deaf parents and who has a CI.

Keywords: Aspect; Language acquisition; Libras; Cochlear implant.

\section{Introdução}

Já se sabe que o processo de aquisição da linguagem das crianças surdas com pais surdos (modelo padrão gramatical) acontece tal qual o das crianças ouvintes. Sobre isso há vasta literatura do Brasil e todos asseveram a analogia em termos de processamento, já que, em ambos os casos, as crianças têm estímulos na sua primeira língua: Libras, quando surdas, e língua portuguesa, quando ouvintes.

No entanto, e se os pais das crianças surdas forem ouvintes não usuários de Libras? Nesse caso, há que se investigar quais são os processos tardios pelos quais essa criança vai passar quando adquirir a Libras na adolescência ou ainda em idade adulta.

E se os pais surdos das crianças surdas optarem pelo procedimento cirúrgico para recuperação da audição, chamado implante coclear? Então, há que se considerar que ela terá um desenvolvimento bilíngue e bimodal na aquisição da linguagem. Bilíngue porque, fatalmente, terá o input em Libras, já que esta é a língua usual de seus pais, e em língua portuguesa, já que estará exposta aos sons da oralidade. Bimodal porque ambas as línguas, Libras e língua portuguesa, apresentam formas distintas de produção e recepção: na primeira, o canal de produção é o espaço à frente do corpo do sinalizador e o canal de recepção é a visão; na segunda, o canal de produção é a oralidade e o canal de recepção é audição.

Entretanto, se os pais forem ouvintes e não sinalizadores e optarem pelo implante coclear, de antemão, descarta-se o desenvolvimento bilíngue/bimodal já que, provavelmente, o estímulo será único e exclusivamente em língua portuguesa, e sobre os prejuízos do não acesso a Libras já há muitas publicações esgotando o tema. Como este não é o nosso caso, não aprofundaremos as discussões a esse respeito. 
O que nos interessa aqui, então, é a comparação de dois processos aquisicionais: da criança surda com pais surdos, monolíngue, e a criança surda com pais surdos que têm implante coclear e, então, torna-se bilíngue/bimodal. Mais especificamente, queremos saber sobre a aquisição da categoria aspectual por essas duas crianças surdas. Neste sentido, nosso objetivo neste artigo é de refletir se: as hipóteses que se ocupam em explicar o processo de aquisição da categoria aspectual por uma criança surda monolíngue, apontadas em Silva (2010), se aplicam também à criança surda que tem implante coclear, é bilíngue/bimodal e tem pais surdos.

Para alcançar tal objetivo, na primeira seção, iremos apresentar considerações sobre os processos de aquisição da linguagem da criança surda com e sem implante coclear, de modo a fundamentar o lugar teórico do qual falamos. Ocuparemo-nos, depois, em explicitar a gramática do adulto, no que tange à categoria dos aspectos lexicais e gramaticais. Depois de demonstrarmos nossos procedimentos metodológicos, passaremos a analisar os dados de ambas as crianças, baseando-nos nas hipóteses de aquisição, com vistas a responder a nossa pergunta inicial.

\section{Fundamentos linguísticos}

Em Silva (2010), observamos os resultados dos dados de uma criança, com pseudônimo de ANA, que tinha acesso irrestrito a Libras por conta de seus pais serem surdos. Os dados analisados se referem à produção do aspecto verbal e a análise aponta para a analogia em relação à aquisição desta categoria gramatical por crianças ouvintes.

A proposta que ora se apresenta diz respeito à aquisição da categoria funcional por um menino surdo com pseudônimo de BRUNO, cujo desenvolvimento linguístico se diferencia do caso da ANA por conta de ele ter recebido o implante coclear (IC). Com ajuda do IC, ele pode ouvir e falar, em alguma medida, a língua portuguesa e, por isso, o seu desenvolvimento linguístico se caracteriza por ser bilíngue e bimodal.

BRUNO está adquirindo naturalmente a língua portuguesa, no dia a dia, por meio de intervenção terapêutica (acompanhamento fonoaudiológico). Em casa, sua mãe surda procura oralizar com seu filho, mas a impressão é que ele, prioritariamente, sinaliza com ela. 
Os dois sistemas linguísticos de BRUNO estão se desenvolvendo, independentemente. Há momentos que ele só sinaliza (sem oralizar). Em casos nos quais ele precisar produzir o sinal de sorrir, por exemplo, que necessariamente, vem acompanhado de uma expressão facial, ele não oraliza, mas usa a boca para produzir a expressão facial da Libras. Em outros momentos, ele só oraliza, sem fazer uso da Libras, mas, na maioria das vezes ele oraliza ao mesmo tempo que sinaliza.

Para se referir às pessoas, por exemplo, ele usa o sinal em Libras e faz a oralização do nome em Língua Portuguesa. 0 uso alternado dos dois sistemas é tanto para a produção quanto para a compreensão. Às vezes, ele olha o que está sendo dito em em Libras, entende, mas responde em português. E é claro que suas expressões da língua portuguesa apresentam características fonológicas e morfológicas típicas da sua idade: papai iel/eu comeu tudo.

BRUNO pode ser considerado bilíngue e bimodal porque tem desempenho em Libras tal qual em língua portuguesa. Isso porque está exposto a ambas as línguas, já que ouve o Português e vê a Libras. Ele é uma criança com implante coclear que, apesar de passar a ouvir alguns sons ao seu redor, continua sendo surda, ou seja, ele continua favorecendo o canal visual em relação ao canal auditivo. Com isso, pode processar as informações linguísticas, em nível morfossintático (categoria aspectual), por meio da visão e da audição.

Em linhas gerais, BRUNO apresentou desempenho semelhante ao das crianças ouvintes, mas sem dúvida, há predominância da Libras. A impressão é a de que ele 'sabe' que é falante de duas línguas e verificamos isso quando ele quer ensinar o pai surdo a falar. 0 pai, que é surdo, vê uma figura de um bule e emite "pula", tentando ensinar a pronúncia de bule ao filho. BRUNO imita, mas em seguida, vê a imagem a que o pai estava se referindo e assim diz: "Não é pula. É toma”. Ou seja, ele não sabe dizer o nome do objeto ainda, mas já identifica que é usado para se tomar café.

Isso posto, vamos passar a conhecer as particularidades da categoria aspectual e as hipóteses do processo de aquisição. 


\section{Categoria aspectual}

Tanto aspecto quanto tempo são noções que se referem à temporalidade dos eventos, porém, sob diferentes perspectivas. A conceituação mais básica de tempo é que ele é uma categoria gramatical dêitica que expressa o momento em que ações verbais acontecem e, por isso, pode definir a existência de três tempos linguísticos: presente, passado e futuro. Sobre questões como essas e sobre outras peculiaridades teóricas da conceituação da categoria tempo há uma vasta literatura, nas quais encontramos diferentes abordagens e discussões dos autores como Benveniste (1989) e Reichendbach (1947). Os tempos linguísticos podem ser aplicados a quaisquer línguas, porém, sua expressividade se dará por expedientes linguísticos distintos.

A expressão da categoria tempo na Libras não conta apenas com léxicos específicos para sua realização, pois muitas vezes é preciso recorrer ao contexto da sinalização para a interpretação temporal. Finau (2004) apresenta a teoria da análise pressuposicional para justificar a leitura temporal de sentenças que não contenham operadores temporais específicos, advérbios ou quantificadores. Tal teoria postula que, mesmo não havendo marcas temporais explícitas (operadores ou flexões) na sentença, é possível perceber o tempo principalmente pelo conhecimento compartilhado entre os interlocutores.

Contrariamente ao conceito de 'dêitico' que o tempo possui, o aspecto é uma categoria não dêitica que marca a duração de um determinado evento ou as fases pelas quais passa. Esta definição advém de Comrie (1976), e é o conceito que tomamos para definir aspecto.

\subsection{Aspecto lexical}

Comrie (1976) aponta que o aspecto lexical se refere às propriedades inerentes do núcleo do verbo e, sob esta perspectiva, os itens lexicais empregados pelos falantes podem descrever - semanticamente - a ação acabada ou em fase. Nesse sentido, o aspecto demonstra sua marca lexical quando identifica os verbos indicando momentaneidade, sem duração por meio da representação semântica do verbo, como 
ocorre em quebrar, morrer, fechar. A marca lexical do aspecto também pode demonstrar a ideia de que há fases internas na situação, sem especificar o começo ou o fim.

Atendo-nos ao aspecto lexical, destacamos que Vendler (1957) foi um dos primeiros pesquisadores a discorrer sobre essa questão e classificou os verbos em estados, atividades, accomplishments e achievements, dependendo dos tipos dos eventos. Estes tipos de situação colocados por Vendler (1957) para classificação verbal tiveram muitas releituras. Testes de compatibilidades e críticas foram feitas à teoria e algumas questões lacunares deste autor foram, detalhadamente, tratadas por Verkuyl (1993), pois ele considera a noção composicional de aspecto. Por isso, em nosso texto, abandonamos Vendler (1957) e aderimos à teoria de Verkuyl (1993).

Diante da abordagem verkuyliana, é preciso que se desenrole uma análise diferenciada no caso de a sentença ter ou não complemento, pois, quando olhamos para o verbo isoladamente, consideramos a semântica implicada nele, porém, quando este verbo é analisado de modo composicional, então, o complemento pode 'alterar' a semântica do verbo.

Ainda com os olhos voltados aos argumentos do verbo para tecer considerações quanto ao valor aspectual, Verkuyl (1993) aponta a necessidade de se perceber se esse argumento interno apresenta uma quantidade específica - specific quantity argument (+SQA) - para receber uma leitura télica, ou se o argumento interno de um verbo for não-específico quanto à quantidade - non-specific quantity (-SQA) -, o verbo receberá uma interpretação atélica.

Para Verkuyl (1993), o cálculo de telicidade de uma derivação é dependente não apenas dos traços lexicais de determinados verbos (Aktionsart), mas também da especificidade do objeto na sentença. Desse modo, Verkuyl (1993) se torna um importante representante da análise composicional do aspecto e com base nesta teoria, vejamos como ocorre a expressividade aspectual na Libras. Para tanto, temos que a oposição semântica verificada entre os verbos procurar e encontrar codifica como se estrutura a situação por eles referida. Procurar é um verbo que codifica a situação como durativa, este é um item lexical imperfectivo. Já encontrar codifica a situação como pontual, ou seja, como não durativa, pois tem uma natureza perfectiva. 


\subsection{Aspecto gramatical}

0 aspecto gramatical pode descrever as mesmas situações do aspecto lexical, mas por meio de marcas morfológicas. Assim, se a ação for acabada, o aspecto é perfectivo e, se ação demonstrar as suas fases, o aspecto será imperfectivo.

0 aspecto também demonstra sua marca gramatical quando apresenta uma forma verbal morfologicamente complexa que será a responsável pela indicação da ação terminada e da pontualidade, como ocorre com (-eu) em choveu. $\mathrm{O}$ aspecto gramatical é dado quando a forma verbal apresenta uma morfologia complexa, capaz de dar enfoque a algum estágio interno de um evento inacabado, como acontece em (-ia) de chovia.

O perfectivo e imperfectivo na Libras também podem ser dados pelo escopo gramatical, e é consenso que a utilização do parâmetro movimento é o responsável pela expressividade do aspecto gramatical.

Quanto ao aspecto perfectivo, é marcado em verbos que denotam fechamento do evento e, segundo Finau (2004), eles são produzidos, morfologicamente, de maneira abrupta e reta. Quanto ao aspecto imperfectivo, a autora diz que, lexicalmente, os verbos expressam evento que dispensam desfecho. Além dos verbos, operadores temporais também podem expressar aspecto imperfectivo. Para representar o aspecto imperfectivo, por meio da morfologia, haverá alteração do parâmetro movimento, pois os sinais terão a velocidade diminuída e serão produzidos mais lentamente e de maneira contínua e sempre na direção de semi-arco. Além do movimento, Finau (2004) coloca que a expressão facial é também um parâmetro que corrobora para que a aspectualidade imperfectiva seja evidenciada.

\section{Procedimentos metodológicos}

Esta pesquisa se caracteriza, como naturalística, longitudinal e espontânea. Os sujeitos investigados foram duas crianças surdas. 0 primeiro sujeito é uma menina surda com pseudônimo de ANA, filha de pais surdos que adquiriu a língua de sinais como sua primeira língua. ANA foi filmada dos 8 meses aos 4:0 anos, em sessões de 30 a 40 minutos cada, sendo que estas aconteciam mensalmente. 
O segundo é um menino surdo, com pseudônimo de BRUNO. Adquiriu a Libras e a língua portuguesa simultaneamente e é filho de pais surdos. A coleta de dados se deu por filmagem, sendo que as imagens foram captadas dos 11 meses aos 3:0, em sessões de 30 a 40 minutos, totalizando 30 horas.

O corpus utilizado neste artigo é de domínio do grupo de pesquisa sobre aquisição de língua brasileira de sinais da UFSC, dirigido por Ronice Muller de Quadros e os dados são disponibilizados e recebem tratamento de análise diferenciado de modo a servir de corpus aos distintos objetos de investigação.

\section{Análise de Dados}

\subsection{Análise das produções aspectuais da criança surda sem IC1}

Segundo Bronckart e Sinclair (1973) e Li e Bowerman (1998), crianças ouvintes, quando estão adquirindo a categorial aspectual, fazem uma associação télico-perfectivo e atélico-imperfectivo. ANA também a faz. Podemos verificar este fenômeno por meio da análise de 124 sentenças diferentes das sentenças de morfologia perfectiva com predicado, denotando ações télicas, bem como morfologia de imperfectivo com predicados atélicos. Desta forma, destacamos alguns exemplos de sentenças perfectivastélicas e imperfectivas-atélicas abaixo transcritas:

\begin{tabular}{|l|l|l|l|l|}
\hline $\begin{array}{l}\text { IX<isso }>\text { QUEBRAR }_{\text {perf }} \\
\text { Isso quebrou. }\end{array}$ & $\begin{array}{l}\text { VER }_{\text {perf }} \text { IX }<\text { lá }> \\
\text { Olha lá. }\end{array}$ & $\begin{array}{l}{ }_{2 s} \text { DAR }_{1 \text { sperf }} \\
\text { Dá para mim. }\end{array}$ & $\begin{array}{l}\text { SENTAR }_{\text {perf }} \text { IX }<\text { aqui }> \\
\text { Sente aqui. }\end{array}$ & $\begin{array}{l}\text { MORRER } \\
\text { A planta morreu. }\end{array}$ \\
\hline
\end{tabular}

Além de ANA ter sinalizado os verbos acima de forma reta e abrupta, os eventos descritos nas sentenças denotam instantaneidade e um ponto de culminância sem estágios sucessivos, que representa o desfecho da ação. Assim, a associação télicoperfectivo ocorre nas produções da criança observada. Com relação à morfologia imperfectiva, o que encontramos foram sentenças do tipo:

\begin{tabular}{|c|c|c|c|}
\hline $\begin{array}{l}\text { BONECA CHORAR imperf } \\
\text { A boneca está chorando. }\end{array}$ & $\begin{array}{l}\text { ESPERAR }_{\text {imperf }} \text { IX }<\text { ai }> \\
\text { Espere ai. }\end{array}$ & $\begin{array}{l}\text { QUERER imperf } \mathrm{IX}<\mathrm{isso}> \\
\text { Quero isso. }\end{array}$ & $\begin{array}{l}\text { FILMAR imperf } \mathrm{I} \\
\text { Você está film }\end{array}$ \\
\hline
\end{tabular}

\footnotetext{
1 Parte dos dados aqui apresentados já foi explorada em Stumpf, Quadros e Leite (2014).
} 
Neste ponto, destacamos que a flexão verbal foi lenta e contínua e os predicados a eles associados são de ordem atélicas, pois não possuem duração definida, necessitando de algum agente externo para mudar o estado (no caso de querer e esperar). Os predicados atélicos não apresentam um fim inerente a sua constituição o que significa que a ação (atividades) pode durar para sempre. Para fins elucidativos, quantificamos nossos achados:

\begin{tabular}{|c|c|c|}
\hline Aspecto & Atélico & Télico \\
\hline Imperfectivo & 16 & 6 \\
\hline Perfectivo & 37 & 65 \\
\hline 124 verbos & 53 & 71 \\
\hline
\end{tabular}

Com estes dados, percebemos que ANA produz muito mais predicados télicos do que atélicos e, então, conforme averiguado por Bronckart e Sinclair (1973), a semântica do verbo (télico ou atélico) se relaciona com a perfectividade ou imperfectividade. Assim, defendemos a ideia de que a ação télica é marcada pela criança como perfectiva, enquanto que a ação de natureza mais atélica recebe flexão de aspecto imperfectivo.

Atentando-nos à flexão, podemos retomar os dados da tabela 1 e pensar nos tipos de movimentos executados pela menina. Tomando os aspectos imperfectivos $(16+6)$, teremos 22 movimentos lentos e contínuos, ao passo que, do total de verbos produzidos por ANA, 102 foram de natureza mais abrupta e reta. Graficamente, podemos assim representar: 
Gráfico 1: Análise da alteração do parâmetro movimento na execução do aspecto pela criança surda sem IC

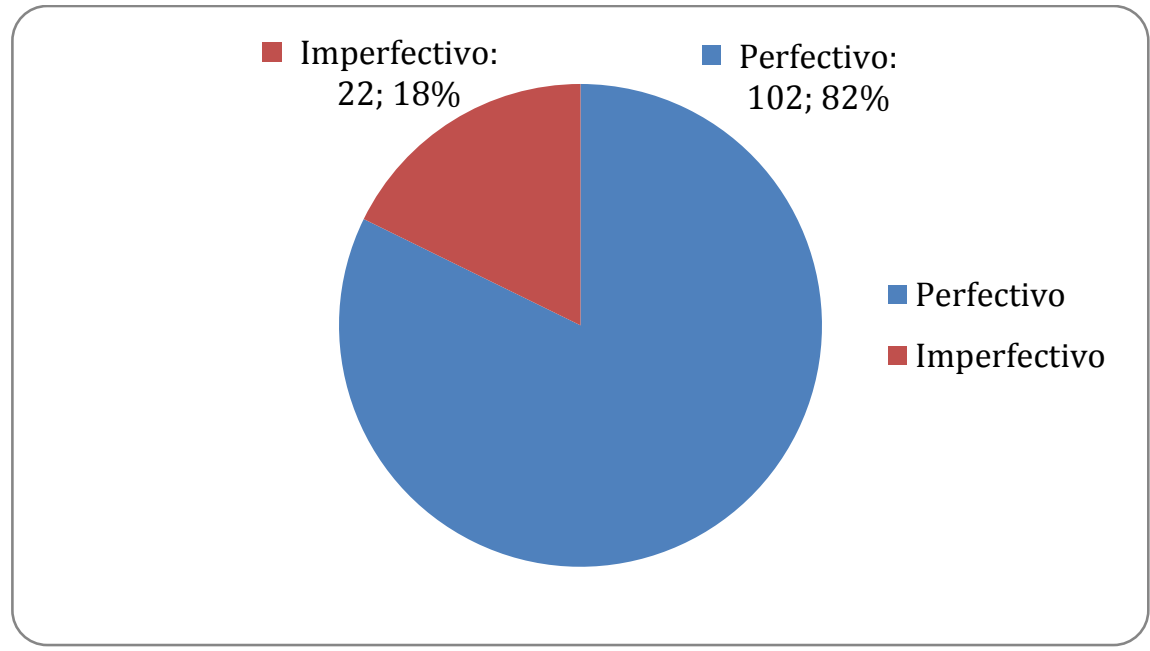

Fonte: Silva (2010)

O movimento é um importante marcador de flexão da Libras e é bastante vasto, devido suas inúmeras possibilidades de execução. Vimos que, se estes verbos forem produzidos de modo lento e com duração contínua, eles irão denotar imperfectividade, ao passo que, se houver tensão, se o sinal contiver um movimento mais abrupto e a direção mais reta, estará marcando perfectividade. Assim, as produções de ANA nos revelam que tais postulados se confirmam, como indica o Gráfico 2.

Gráfico 2: Aspectos perfectivos e imperfectivos produzidos pela criança surda sem IC

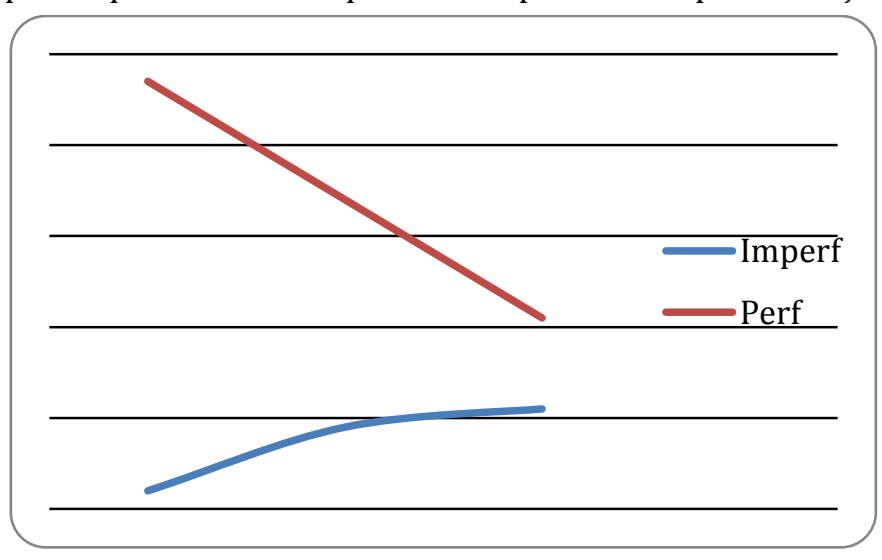

Fonte: Silva (2010)

Analisando o gráfico 2, mencionamos que, na fase que compreende a idade de 1:0 a 2:0, ANA produziu apenas dois aspectos imperfectivos, mas 47 perfectivos. Com a idade de 2:0 a 3:0, a menina realiza nove imperfectivos contra 34 perfectivos e, finalmente, na fase que vai dos 3:0 aos 4:0, ela fez onze imperfectivos e 21 perfectivos. Com isso em mãos, podemos ver o crescente uso do imperfectivo e o declínio do 
perfectivo com o passar dos anos. Também conseguimos perceber que há primeiro a ascendência da associação télico-perfectivo para somente depois ocorrer a aquisição do atélico-imperfectivo. Portanto, corroboramos com Reis e Lopes (2008) que, em sua pesquisa, encontrou formas imperfectivas só aos 2:3 e, antes disso, encontrou verbos perfectivos com predicados télicos. No nosso caso, vemos que, quanto mais jovem a criança, maior a associação. Com isso, inferimos que o adulto não reproduz o uso de flexões perfectivas apenas com télicos como faz a criança na maioria das vezes.

Agora que já constatamos que a criança associa o télico ao perfectivo e o atélico ao imperfectivo, podemos asseverar que ANA já adquiriu a categoria aspectual e, a partir disso, é possível pensarmos em outra situação: a criança já adquiriu a categoria tempo?

$\mathrm{Na}$ fase investigada por nós, não houve a ocorrência destes três operadores em sua forma raiz, e nenhuma variação destes (gradação temporal, por exemplo), tampouco da demonstração de intervalos do passado ou de futuro tais como 'anteriormente' e 'posteriormente' e nem mesmo encontramos cenas de ANA sinalizando advérbios de tempo. Com isso, estamos entendendo que a criança ainda não adquiriu as propriedades de expressão da categoria tempo.

Constatamos em nossos dados que a criança já é capaz de produzir expedientes linguísticos que demonstram as propriedades internas da situação, o desenvolvimento do evento, o aspecto. Atentamo-nos também para o fato de que há, desde o início do processo de aquisição do aspecto, a 'manifestação do tempo' através da aspectualidade da sentença. Neste sentido, confirmamos que o tempo é dado pelas marcas aspectuais tal qual apontado nas pesquisas de Antinucci e Miller (1976) e de Osawa (1999), os quais alegam que, na ausência de tense, a interpretação temporal pode ser dada pela aspectual, uma vez que as duas categorias se desenvolvem independentemente. Conforme vemos nos dados, a criança usa o passado perfectivo quando a situação é télica e usa morfologia de presente com verbos que apresentam traço [-télico]. Da mesma forma, asseveramos que os aportes teóricos de Johnson e Fey (2006) e Reis e Lopes (2008) encontram adesão no caso da Libras.

Já que nossos dados revelam a presença do aspecto e a ausência da expressão de tempo por operadores, corroboramos com as pesquisas de Jacobson (1986), Osawa (1999) e Lopes e Quadros (2005) que atestam que as crianças são precocemente capazes de descobrir a natureza dos acontecimentos, se são repentinos, durativos, se 
ocorrem só uma vez e se são completos ou não; só depois disso elas começam a organizar a representação do tempo em uma linha temporal. ANA já adquiriu a noção de temporalidade não dêitica (aspecto), mais ainda não adquiriu a categoria tempo.

Inferimos que ANA vai aprender as marcas para categoria de tempo - via operadores temporais e aquelas outras já apresentadas - posteriormente, já que a categoria funcional aspecto já emergiu. Em nossos dados, identificamos que ANA, com a idade de 1:5, já produz sentenças perfectiva e, com 2:11, começa a produzir muito mais sentenças imperfectivas, porém, até o final de nossa investigação, quando a menina estava com 4:0, não encontramos marcadores temporais. Desta forma, reiteramos o posicionamento dos autores (OSAWA, 1999; JACOBSON, 1986; ANDERSEN, 1986; LOPES; QUADROS, 2005) quanto à primazia do aspecto, pois apontam que a criança adquire primeiro a noção de temporalidade não dêitica, ou seja, a categoria de aspecto mesmo antes de adquirir a categoria tempo. Isso posto, ou seja, nossa adesão ao fato de ANA ter adquirido aspecto e não tempo, temos que questionar: como são dadas, por ela, as marcações de tempo dêitico?

Conforme Antinucci e Miller (1976), Osawa (1999), Johnson e Fey (2006), Reis e Lopes (2008) e Finau (2004), há expressão de tempo por meio da aspectualidade da sentença. Neste sentido, alegamos a associação télico-perfectivo-passado e atélicoimperfectivo-presente a partir dos exemplos apresentados: ANA estava interagindo com sua mãe no quintal da casa quando sinalizou: ACABAR IX<galinha>.

Ela produziu este verbo de maneira muito rápida, o sinal é curtinho e não há muito afastamento das mãos. ANA produziu este sinal com morfologia perfectiva (movimentos abruptos e retos) e, com isso, podemos concordar com a descrição aspectual da Libras encontrada em Finau (2004) e inferir que ele corresponde ao tempo passado na fala da criança em fase de aquisição da linguagem. Assim sendo, é possível percebermos que há uma tradução possível para ACABOU.

Outra sentença aspectualizada realizada por ANA da qual pudemos extrair a leitura temporal e inferir a associação perfetivo-passado e imperfectivo-presente é a que segue: CAIR $_{\text {perf }}<$ bola $>$.

ANA sinaliza o verbo CAIR marcado perfectivamente, pois, além da semântica do verbo, o movimento do sinal foi produzido muito rápido e de modo muito curto, sem alongamento nem lentidão nesta sinalização. Com isso, podemos perceber que, de fato, o 
processo de aquisição da linguagem da ANA está ocorrendo de modo análogo ao das crianças ouvintes, pois, inferimos, a fala não seria de caia, mas sim de caiu, ou seja, com morfologia perfectiva, a qual a criança surda está realizando.

Estes exemplos nos permitem averiguar que, de fato, a criança em questão associa, em sua produção linguística, o 'tempo' (não marcado linguisticamente) com aspecto, sob as ordens perfectivo-passado e imperfectivo-presente. Um exemplo que demonstra associação do imperfectivo encontra-se na seguinte sentença: CHORAR imperf $_{\text {a }}$ IX $<$ boneca $>$.

Nesta sentença, o verbo chorar foi marcado imperfectivamente. Isso é possível de constatarmos quando consideramos que o sinal raiz de chorar teve seu movimento alterado, pois ANA o produziu de modo lento e contínuo e não com movimento com velocidade 'normal' e 'descontínuo' como seria a produção do sinal raiz. Na gramática do adulto, conforme nos aponta Finau (2004), a expressão facial também sofreria alteração para a configuração destes sinais, porém, como a flexão ainda é incipiente, a realização se deu com a alteração de apenas um parâmetro. Por conta do verbo ter sido produzido imperfectivamente, temos a ideia da ação acontecendo neste momento. A menina mostra a boneca para a câmera e diz que ela está chorando, que a ação ainda não acabou e, por querer referir-se ao presente, escolhe usar a morfologia de imperfectivo. Neste sentido, nossa tradução para esta sentença é: "A boneca está chorando".

Outra sentença que manifesta que o uso do imperfectivo se associa ao presente é encontrada na seguinte produção: APRENDERimperf $\mathrm{IX}<\mathrm{eu}>$. Aqui também podemos constatar a marca morfológica do imperfectivo sendo usada, pois o sinal aprender em sua raiz é executado com movimento 'reto'. Nesse caso, entretanto, ANA o faz de maneira lenta e contínua, alterou a velocidade e, consequentemente, o padrão de movimento do sinal raiz, ou seja, ela flexionou o verbo para aspecto imperfectivo, o que fez com que houvesse uma referência ao tempo presente. Se precisarmos considerar o contexto para fazer uma leitura-interpretação da frase, destacaríamos que a menina tinha acabado de produzir um sinal 'certo', e foi elogiada pela mãe com a expressão: APRENDER $_{\text {imperf }}$ (Está aprendendo) SABER imperf (Você sabe), ou seja, está falando de um evento que está acontecendo agora, neste momento, no presente e, por isso mesmo, utilizou-se da morfologia imperfectiva. Imediatamente, a menina concorda com a mãe e 
sinaliza: "Estou aprendendo". Assim podemos ver que Finau (2004) tinha razão quando dizia que havia associação entre presente-imperfectivo.

\subsection{Análise das produções aspectuais da criança surda com implante coclear}

Analisamos 186 sentenças diferentes, nas quais pudemos identificar a ocorrência de morfologia perfectiva com predicado denotando ações télicas, morfologia de imperfectivo com predicados atélicos, da mesma forma como fazem as crianças ouvintes e como fez a criança surda sem implante coclear (IC) investigada por nós.

BRUNO usava o perfectivo em Libras por meio de movimentos retos e abruptos, enquanto fazia o imperfectivo por meio de movimentos lentos e contínuos. Ainda em português, utilizava a morfologia -ei para perfectivo e a morfologia -ava para o imperfectivo.

Da mesma forma que ANA fazia, BRUNO associava esses aspectos de acordo com o traço télico ou atélico, ou seja, fazia uso de predicados télicos quando queria apresentar fim inerente e usava predicados atélicos quando os eventos não apresentavam um fim inerente. Esses são alguns exemplos de sentenças perfectivastélicas: "Eu gostei do presente" e "Eu dei pra você".

Além de BRUNO ter sinalizado os verbos acima de forma reta e abrupta, ele também oralizou com a morfologia do perfectivo, pois os eventos descritos nas sentenças denotam instantaneidade e sem estágios sucessivos e um ponto de culminância, que representa o desfecho da ação. Assim, a associação télico-perfectivo ocorre nas produções da criança com IC. Com relação à morfologia imperfectiva, o que encontramos foram sentenças do tipo:

\begin{tabular}{|l|l|l|l}
\hline Você está conversando. & Espere um pouco. & Eu gosto do sapo. & Eu não fecho o olho.
\end{tabular}

Neste ponto, destacamos que a flexão verbal foi lenta e contínua, e os predicados a eles associados são de ordem atélicas, pois não possuem duração definida, necessitando de algum agente externo para mudar o estado. Os predicados atélicos não apresentam um fim inerente à sua constituição, o que significa que a ação pode durar para sempre. Para fins elucidativos quantificamos abaixo nossos achados: 
Tabela 2 - Relação de aspecto e telicidade em criança surda sem IC - BRUNO

\begin{tabular}{c|c|c}
\hline Aspecto & Atélico & Télico \\
\hline Imperfectivo & 23 & 8 \\
\hline Perfectivo & 55 & 100 \\
\hline 186 verbos & 78 & 108 \\
\hline
\end{tabular}

Fonte: Silva (2010)

Com estes dados, percebemos que BRUNO produz muito mais predicados télicos do que atélicos. Assim, defendemos a ideia de que a ação télica é marcada pela criança como perfectiva, enquanto a ação de natureza mais atélica recebe flexão de aspecto imperfectivo.

Atentando-nos à flexão, podemos retomar a Tabela 2 e pensar nos tipos de movimentos executados pelo menino surdo com IC. Tomando os aspectos imperfectivos $(23+8)$, teremos 31 movimentos lentos e contínuos, ao passo que, do total de verbos produzidos por BRUNO, 155 foram de natureza mais abrupta e reta. Graficamente, podemos assim representar:

Gráfico 3: Análise da alteração do parâmetro movimento na execução do aspecto pela criança surda com IC

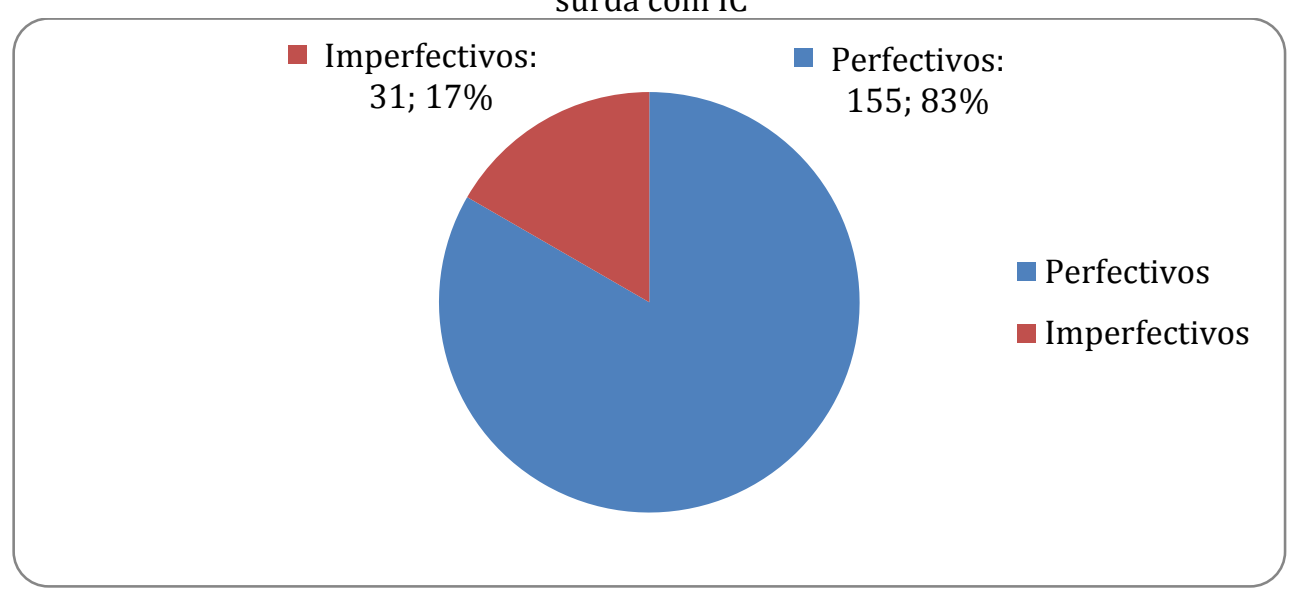

Fonte: Silva (2010)

Um exemplo disso é que, em relato sobre uma festa que foram em sábado anterior, BRUNO diz: "Você sumiu". A partir disso, observamos que ele produziu a sentença completa em português (com Sujeito e verbo flexionado com morfologia perfectiva), mas em Libras sua produção foi apenas do verbo sumir, ou seja, houve omissão do sujeito. 0 verbo foi produzido com tensão e com um movimento mais 
abrupto e na direção mais reta: inferimos que ele marcou a perfectividade também em Libras.

Num outro momento, referindo-se a uma peça do jogo que não estava mais na caixa, ele disse que o rato a comeu. De novo, produziu a sentença completa em português: "Ele comeu". Em Libras, produziu apenas o verbo com a morfologia perfectiva.

Já em relação à morfologia imperfectiva, vemos BRUNO utilizando sinal do verbo com movimentos mais lentos e contínuos, como, por exemplo, quando sua mãe perguntou o que ela estava fazendo, e o menino a respondeu: "Conversando". Aqui houve o registro da produção em língua oral e em Libras e apenas do verbo e não da sentença. Em ambas as línguas ocorreram os processos de flexão morfológica para imperfectivo. BRUNO também fez uso do imperfectivo quando oralizou ao mesmo tempo em que sinalizou: "Comendo".

Indiferente de a modalidade ser oral auditiva ou espaço-visual, observamos que é mais fácil para as crianças produzirem marcadores de aspecto imperfectivo quando a situação é de eventos atélicos e produzem melhor o marcador perfectivo com eventos télicos. Isso ocorre, segundo a Basic Child Grammar Hypothesis, porque a criança está preparada desde seu nascimento para perceber o contraste entre processo e resultado. Isto implica numa avaliação de acionalidade (predicados) como processo e aspecto (formas) como resultado.

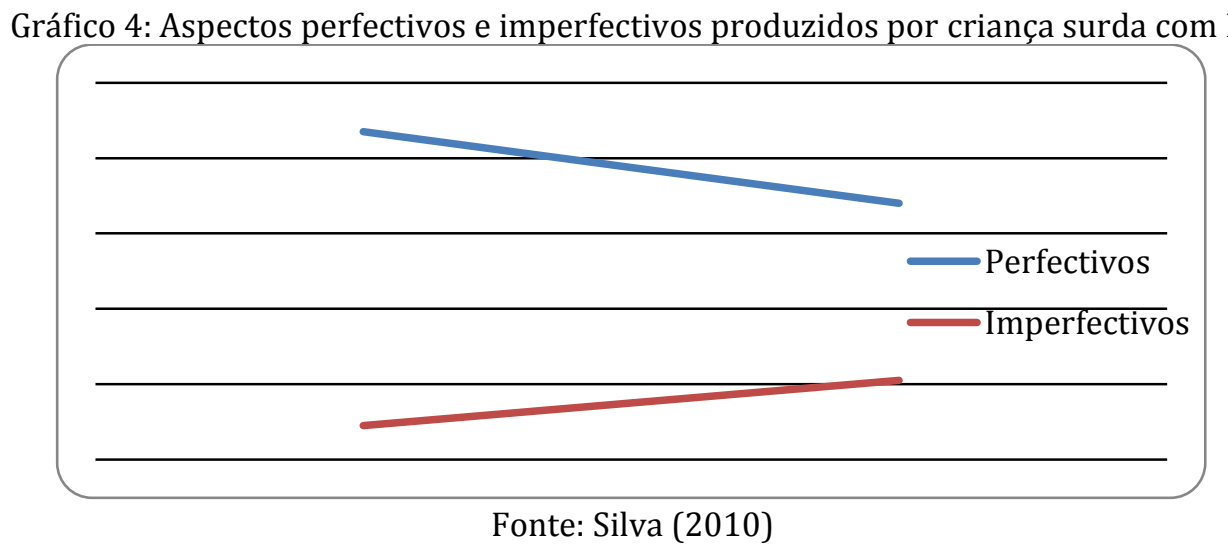

Analisando o Gráfico 2, mencionamos que, na fase que compreende a idade de 1:0 a 2:0, BRUNO produziu apenas nove aspectos imperfectivos, mas 87 perfectivos. 
Com idade de 2:0 a 3:0, o menino surdo com IC realizou 21 imperfectivos contra 68 perfectivos. Com isso em mãos, podemos ver o crescente uso do imperfectivo e o declínio do perfectivo com o passar dos anos. Percebemos também que primeiro há ascendência da associação télico-perfectivo para somente depois ocorrer a aquisição do atélico-imperfectivo, pois vemos que, quanto mais jovem a criança, maior a associação.

Constatamos que a criança surda com IC assim como a criança surda sem IC associam o télico ao perfectivo e o atélico ao imperfectivo. Podemos asseverar, portanto, que ambos já adquiriram a categoria aspectual, mas, a partir disso, é possível pensarmos em outra situação: a criança surda com IC também não adquiriu a categoria tempo ainda? Vamos às constatações:

BRUNO não produziu sinais de passado, presente e futuro na sua forma raiz e nenhuma variação deles (gradação temporal, por exemplo), tampouco produziu sinais com demonstração de intervalos do passado ou de futuro, tais como 'anteriormente' e 'posteriormente'. Não encontramos, ainda, cenas de BRUNO sinalizando advérbios de tempo. Com isso, estamos entendendo que a criança surda com IC ainda não adquiriu as propriedades de expressão da categoria tempo.

Por ora, constatamos em nossos dados que a criança já é capaz de produzir expedientes linguísticos que demonstram as propriedades internas da situação, o desenvolvimento do evento, o aspecto. Atentamo-nos também para o fato de que há, desde o início do processo de aquisição do aspecto, a 'manifestação do tempo' através da aspectualidade da sentença.

Conforme vemos nos dados, a criança surda com IC usa o passado perfectivo quando a situação é télica e usa morfologia de presente com verbos que apresentam traço [-télico]. BRUNO já adquiriu a noção de temporalidade não dêitica (aspecto), mas ainda não adquiriu a categoria tempo. Nossa primeira análise averigua a hipótese da primazia do aspecto. Diante de nossa adesão ao fato de BRUNO ter adquirido aspecto e não tempo, questionamos: como são dadas, por ele, as marcações de tempo dêitico?

A criança surda com implante coclear faz uso da morfologia perfectiva (tanto em português como em Libras) para passado. Em situação de uso do verbo DORMIR especificamente, BRUNO estava interagindo com sua mãe surda em Libras e quando ela

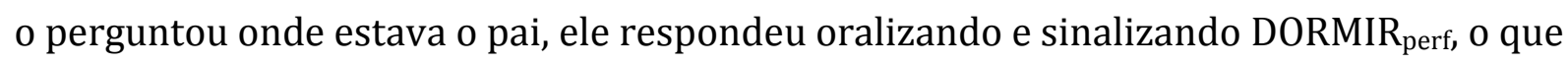
nos faz ter leitura de dormiu. 
Aqui, destacamos, conforme Quadros, Cruz e Pizzio (2012), que há uma dissociação entre o sistema fonológico da Libras e do Português. Observamos que, primeiro, BRUNO oralizou e, depois, quando sinalizou, oralizou simultaneamente. Considerando que BRUNO é uma criança surda com IC e apresentou a mesma produção para a sentença que ANA, surda sem implante coclear, podemos entender que os aspectos morfossintáticos de ambas as línguas permanecem dissociados. Isto porque, segundo as autoras, no caso de aprendizes bilíngues/bimodais, há a presença de canais articulatórios diferentes, ou seja, as mãos e a visão no caso da Libras e a audição e a voz, no caso do Português. BRUNO, devido ao IC, pode ouvir o Português e ver a Libras.

Outra sentença produzida pela criança com IC foi quando interrogado pela mãe sobre o motivo de não ter falado determinada frases ele responde em Libras: SABER$\mathrm{NÃO} \mathrm{O}_{\text {imperf. }}$

BRUNO também expressou a marca morfológica do imperfectivo, pois o sinal SABER-NÃO em sua raiz é executado com a configuração de mão em B, na testa, com movimento semicircular para fora. Entretanto, BRUNO o fez de maneira lenta e contínua, alterou a velocidade e, consequentemente, o padrão de movimento do sinal raiz, ou seja, flexionou o verbo para aspecto imperfectivo, o que fez com que houvesse uma referência ao tempo presente. 0 que é interessante nesse caso é que, logo após ter feito uso do imperfectivo em Libras, mediante insistência da sua mãe de que ele sabia, BRUNO respondeu: "Não sei" (Não sabe) em português. Percebemos a ausência da morfologia -ei, mas contextualmente a sentença se refere a presente. Então, as pistas do discurso nos apresentam produção coerente em ambas as línguas.

Uma vez mais BRUNO valeu-se da produção aspectual também em português, o que nos leva a perceber o tempo aspectualmente dado. Por exemplo: ele oralizou a sentença inteira: "Minha prima fica sozinha porque minha tia vai trabalhar". 0 contexto de fala de BRUNO na produção da sentença em português é que ele estava no colo da mãe indo para a casa da tia. A mãe explicou o que iriam fazer lá e ele repetiu para a câmera, explicando o motivo da saída. 


\section{Considerações finais}

Este artigo tratou da investigação da aquisição da categoria aspectual por duas crianças surdas, sendo que uma delas passou pelo procedimento cirúrgico de implante coclear. Ambas estavam adquirindo a Língua Brasileira de Sinais (Libras) como primeira língua. Para refletir sobre isso, tomamos a teoria linguística geral, baseando-nos em Comrie (1976) e na linguística da Libras (FINAU, 2004). Em ambos os estudos, as considerações recaíram sobre o enfoque lexical e gramatical do aspecto e sobre a oposição aspectual entre perfectivo e imperfectivo.

Constatamos que as hipóteses explicam o processo de aquisição da categoria aspectual por uma criança surda (modelo padrão gramatical: monolíngue), apontadas em Silva (2010). As hipóteses se aplicam também à criança surda com pais surdos que tem implante coclear (bilíngue/bimodal).

Percebemos que tanto ANA quanto BRUNO produzem predominantemente aspecto lexical perfectivo, fenômeno análogo à criança ouvinte adquirindo o aspecto na língua falada. Encontramos também produções de aspecto gramatical por meio de flexão dos verbos tanto na sinalização de ANA quanto de BRUNO. Estas flexões ocorreram via alteração morfológica (movimento), e são de ordem perfectiva, majoritariamente, tal qual apontam as teorias sobre aquisição do aspecto gramatical em línguas orais.

Com isso, identificamos que uma criança surda que tem estimulação da língua oral, por meio da presença do implante coclear, e, por consequência, uma orientação bilíngue, apresenta as mesmas produções linguísticas da categoria aspectual em Libras de um usuário monolíngue desta língua.

Esses dados suportam, portanto, que as crianças surdas com implante coclear parecem ser beneficiadas com o acesso irrestrito à Libras. A aquisição de uma língua pelos olhos favorece a aquisição da linguagem por essas crianças e favorece um desenvolvimento bilíngue de forma mais apropriada.

A aquisição precoce da língua de sinais pode ser um importante fator a ser considerado no desenvolvimento linguístico de crianças surdas que realizam a cirurgia para a colocação do IC precocemente. 


\section{Referências}

ANDERSEN, R. The acquisition and use of Spanish and English as first and second languages. Washington DC: TESOL, 1986.

ANTINUCCI, F.; MILLER, R. How children talk about what happened. Journal of Child Language, v. 3, p. 167-189, 1976.

BENVENISTE, E. Problemas de linguística geral II. Trad; Eduardo Guimarães ET. All. Campinas: Pontes, 1989.

BRONCKART, J-P.; SINCLAIR, H. Time, tense and aspect. Cognition, v. 2, p. 107-130, 1973.

COMRIE, B. Aspect: an introduction to the study of verbal aspect and related problems. Londres: Cambridge University Press, 1976.

FELIPE, T. A relação sintático-semântica dos verbos na Língua Brasileira de Sinais (LIBRAS). Curso de Pós-Graduação em Linguística e Filologia (Doutorado em Linguística e Filologia), Universidade Federal do Rio de Janeiro, Rio de Janeiro, 1998.

FINAU, R. A. Os sinais de tempo e aspecto na LIBRAS. 2004. 238 f. Tese (Doutorado em Letras) - Curso de Pós-Graduaçao em Letras, Universidade Federal do Paraná, Curitiba, 2004.

JACOBSON, J. L. et al. Paralinguistic features of adult speech to infants and small children. Child Development, v. 54, n. 2, p. 436-442, 1986.

JOHNSON, B.; FEY, M. Interaction of lexical and grammatical aspect in toddlers' language. Journal of Child Language, v. 33, p. 419-435, 2006.

LI, P.; BOWERMAN, M. The acquisition of lexical and grammatical aspect in Chinese. First Language, v. 18, p. 311-350, 1998.

LOPES, R.; QUADROS, R. Traços semânticos na aquisição da linguagem: há efeitos de modalidade de língua? Revista da ABRALIN, v. 4, n. 1 e 2, p. 75-108, 2005.

OSAWA, F. The relation between Tense and Aspect: The Emergence of the Tsystem. UCL Working Papers in Linguistics, v. 11, p. 521-543, 1999.

QUADROS, R. M. de; CRUZ, C. R.; PIZZIO, A. L. Memória fonológica em crianças bilíngues bimodais e crianças com implante coclear. ReVEL, v. 10, n. 19, 2012.

REICHENBACH, H. Elements of Symbolic Logic. New York: Macmillan Company, 1947.

REIS, F. E. B; LOPES, R. E. V. Tempo e aspecto na linguagem de uma criança brasileira. Língua, literatura e ensino, v. 3, p. 473-481, Maio 2008. 
SILVA, L. Investigando a categoria aspectual na aquisição da língua brasileira de sinais. 2010. 154 f. Dissertação (Mestrado em Linguística) - Curso de Pós-Graduação em Linguística, Universidade Federal de Santa Catarina, Florianópolis, 2010.

STUMPF, M. R.; QUADROS, R. M.; LEITE, T. A. Estudos da Língua Brasileira de Sinais. Volume II. Insular, 2014.

VENDLER, Z. Verbs and times. Philosophical Review, v. 66, n. 2. p. 143-160, 1957.

VERKUYL, H. J. A theory of aspectuality: the interaction between temporal and atemporal structure. New York: University of Cambridge, 1993.

Recebido em março de 2014.

Aceito em junho de 2014. 